\title{
Risk of violence from the man involved in the pregnancy after receiving or being denied an abortion
}

\author{
Sarah CM Roberts, M Antonia Biggs, Karuna S Chibber, Heather Gould, Corinne H Rocca and Diana Greene Foster
}

\begin{abstract}
Background: Intimate partner violence is common among women having abortions, with between $6 \%$ and $22 \%$ reporting recent violence from an intimate partner. Concern about violence is a reason some pregnant women decide to terminate their pregnancies. Whether risk of violence decreases after having an abortion, remains unknown.
\end{abstract}

Methods: Data are from the Turnaway Study, a prospective cohort study of women seeking abortions at 30 facilities across the U.S. Participants included women who: presented just prior to a facility's gestational age limit and received abortions (Near Limit Abortion Group, $\mathrm{n}=452$ ), presented just beyond the gestational limit and were denied abortions (Turnaways, $\mathrm{n}=231$ ), and received first trimester abortions (First Trimester Abortion Group, $n=273$ ). Mixed effects logistic regression was used to assess the relationship between receiving versus being denied abortion and subsequent violence from the man involved in the pregnancy over 2.5 years.

Results: Physical violence decreased for Near Limits (adjusted odds ratios (aOR), 0.93 per month; 95\% Confidence Interval (Cl) $0.90,0.96)$, but not Turnaways who gave birth ( $P<.05$ versus Near Limits). The decrease for First Trimesters was similar to Near Limits $(P=$.324). Psychological violence decreased for all groups $(\mathrm{aOR}, 0.97 ; \mathrm{Cl} 0.94$, 1.00), with no differential change across groups.

Conclusions: Policies restricting abortion provision may result in more women being unable to terminate unwanted pregnancies, potentially keeping them in contact with violent partners, and putting women and their children at risk.

Keywords: Abortion, Intimate partner violence

\section{Background}

Experiencing violence, especially from intimate partners, is common among women having abortions, with $6 \%$ to $22 \%$ reporting recent violence from an intimate partner [1-5]. Concern about violence is a reason some pregnant women decide to terminate their pregnancies [6-9]. In particular, women who report violence as a reason for abortion describe not wanting to expose children to violence and believing that having the baby will tether them to an abusive partner [6].

Whether having an abortion actually allows women to evade intimate partner violence (IPV) remains unknown.

\footnotetext{
*Correspondence: Antonia.Biggs@ucsf.edu

Advancing New Standards in Reproductive Health (ANSIRH), University of California, San Francisco, 1330 Broadway, Suite 1100, Oakland, CA 94612, USA
}

One prospective study in New Zealand found elevated levels of past year IPV among women who had abortions compared to women who gave birth and no differences between women who had abortions and women who had not been pregnant [10]. However, the difference in IPV between women who had an abortion and women who gave birth was no longer statistically significant once confounders were controlled. The New Zealand study assessed IPV from any intimate partner, not necessarily from the man involved in the pregnancy (MIP). Focusing on the MIP is important because this is the person to whom a woman would be linked if she carried the pregnancy to term.

The aim of this paper is to examine changes in violence from the MIP among women receiving versus being denied 
abortion over 2.5 years after seeking an abortion. Comparing changes in violence over time between women receiving versus denied abortion has the benefit of being able to better match groups of women with respect to important confounding factors, such as pregnancy intentions and violence, that can lead women to become pregnant and also decide to terminate a pregnancy. Thus, women denied abortions better represent what women's experiences would have been had they not terminated the unwanted pregnancy and allow for the possibility of causal inference regarding outcomes subsequent to abortion.

\section{Methods}

Data for this paper come from the Turnaway Study, a prospective cohort study of women who all sought, but did not all receive, abortions at 30 abortion facilities in the United States. Women were recruited when they sought abortion and were interviewed by telephone one week later. The Turnaway Study is following participants for five years, interviewing them by telephone biannually. This paper presents findings from the first 2.5 years of data collection. The University of California, San Francisco's Committee for Human Research granted ethical approval for the study. All participants provided written informed consent.

Participants were English- and Spanish-speaking women with no known fetal anomalies or demise, 15-years-old or older, presenting at one of the study facilities between January 2008 and December 2010 (the recruitment period). Facilities with the latest gestational age limit for providing abortion within 150 miles were eligible. All but two facilities approached participated; one was replaced with a facility with a similar catchment area, identical gestational limit and similar patient volume. Participating facility limits ranged from 10 weeks through the end of the second trimester, with four having limits in the first trimester, eight between 14 and less than 20 weeks, and 18 after 20 weeks. Details about the study and facilities have been published previously [11-16].

Women were eligible for the study and assigned to one of three study groups based on their gestational age at abortion-seeking. Women presenting for abortion within two weeks under a facility's gestational age limit and receiving an abortion were assigned to the Near Limit Abortion Group; women presenting for abortion up to three weeks over the limit and denied abortion at that facility were assigned to the Turnaway Group. Near Limit Abortion versus Turnaway is the main comparison in this study. For every Turnaway, we recruited two women for the Near Limit Abortion Group and also one woman receiving an abortion in the first trimester for the First Trimester Abortion Group. The First Trimester Abortion Group was included to assess how the experiences of women in the Near Limit Group compared to the more typical experience of abortion in the U.S., where $90 \%$ of abortions occur in the first trimester [17].

Of eligible participants approached, 37.5\% consented, with $85 \%$ of those consenting $(n=956)$ completing the baseline interview [16]. Seventy two percent of those completing the baseline interview were retained at the sixth interview (2.5 years). There was no differential participation across the two main study groups (Near Limit Abortion Group and Turnaway Group), but fewer women eligible for the First Trimester Abortion Group participated. There was no differential loss to follow up by study group or by baseline violence over the 2.5 years. Of the 956 who completed a baseline interview, 452 were in the Near Limit Abortion Group, 231 in the Turnaway Group, and 273 in the First Trimester Abortion Group. Some women in the Turnaway Group received an abortion elsewhere or miscarried subsequent to being denied the abortion at the recruitment facility. At one facility with a gestational limit of 10 weeks, 90\% of Turnaways received an abortion elsewhere or miscarried. All of the 76 participants from this facility were excluded from analyses. Two Near Limit Abortion Group and one First Trimester Group participants later reported that they had not had the abortion and were excluded from the analyses. Women who did not know who the man involved in the pregnancy was or reported that the pregnancy was a result of rape $(n=15)$ were not asked questions about the MIP at follow-up interviews and were excluded from the analyses. The sample thus includes 862 participants, with 405 in the Near Limit Abortion Group, 156 Turnaways who had a birth (Turnaway Births), 48 Turnaways who had an abortion $(n=43)$ or miscarriage $(n=5)$ (Turnaway No Births), and 253 in the First Trimester Abortion Group.

Two types of violence from the MIP were considered as outcome variables: physical and psychological. These outcome variables were based on questions about physical violence (that is, 'pushed, hit, slapped, kicked, choked, or physically hurt in any way by another person') and psychological violence (that is, 'frightened for your safety as a result of anger or threats made by another person') in the last six months. We also asked whether the perpetrator of the most recent violent episode was the MIP. The violence questions were asked at each biannual interview. Violence questions were modified from California's Maternal and Infant Health Assessment Survey [18]. During the baseline interview, participants were also asked about physical and psychological violence in the year preceding the interview. We used dates of conception and of violence to determine whether the violence occurred during or before pregnancy.

Study group was the main independent variable and included Near Limit Abortion Group (as reference); Turnaway Births (Turnaways with a live birth, including 15 who placed their baby for adoption); Turnaway No 
Births (Turnaways who received an abortion elsewhere or miscarried) and First Trimester Abortion Group. Because we were interested in both Near Limit versus Turnaway Birth and Near Limit versus First Trimester comparisons, Near Limit as the reference allowed simultaneous comparisons of both sets of study groups. Months was the time variable and was measured in months since recruitment. Study Group X Months interaction terms allowed examination of group-specific change over time.

Covariables included potential confounders of the relationship between study group and subsequent violence, all measured at baseline. We measured race/ethnicity (White, Black, Hispanic/Latina, Other); age in years; employment (employed full or part time versus unemployed); union status (married, cohabiting, not-cohabiting never married, divorced/widowed); history of child abuse/neglect, or reporting having ever experienced physical abuse, neglect, or sexual abuse during childhood; raising children (no live births, living with all biological children, one or more biological children cared for by someone else); grew up in a household with someone with an alcohol or drug problem; grew up in a household with someone with a psychological disorder; previous depression or anxiety diagnosis; alcohol problem symptom the month before pregnancy recognition, with those reporting having a drink first thing in the morning to steady nerves or get rid of a hangover and those reporting that they were unable to remember what happened the night before because of drinking coded as having a problem symptom; and illicit drug use the month before pregnancy recognition, with any marijuana, heroin, cocaine, methamphetamine use or prescription drug misuse coded as illicit drug use.

We used three analytical approaches. First, we used mixed effects linear, logistic and multinomial logistic regression to compare baseline characteristics of study groups. The mixed effects regression models included random intercepts for facility to account for clustering of participants by site. Second, longitudinal analyses examining associations between study group and violence over time were conducted with mixed effects multivariate logistic regression. Longitudinal analyses included data from the first six interviews, from one week through 2.5 years after abortion-seeking, and included all available data. Random intercepts for facility and for individual were included to account for facility and individual-level clustering. Random slopes for individual did not improve any model fits and, thus, were not included. Third, in the cases where change over time differed between the Near Limit and Turnaway Births groups, a model with Turnaway Births as the reference group was estimated to be able to describe change over time directly for the Turnaway Births group and not describe change solely in relation to the Near Limit Group. All analyses were conducted in Stata 12.0.

\section{Results}

Participant baseline characteristics are shown in Table 1. Compared to the Near Limit Abortion Group, the Turnaway Birth Group was younger, less likely to be employed and less likely to be raising children. A smaller proportion of women in the Turnaway No Birth Group than in the Near Limit Abortion Group reported a history of child abuse/neglect and growing up in a household with someone with a drinking or drug problem. Compared to the Near Limit Abortion Group, the First Trimester Abortion Group was more likely to be White, employed and report growing up in a household with someone with a psychological disorder. As expected due to study design, groups differed significantly on gestational age at recruitment.

In the six months prior to baseline (to match the timeframe for subsequent measures of violence), $5 \%$ of the participants experienced physical violence from the MIP and 3\% reported psychological violence from the MIP (See Table 1). There were no statistically significant differences across study group in either physical or psychological violence from the MIP in the six months prior to baseline.

In the year prior to baseline, violence from the MIP occurred both before and during pregnancy, with about $3 \%$ reporting physical violence before pregnancy only, $3 \%$ during pregnancy only and $1 \%$ both before and during pregnancy (Figure 1, not shown in a table). For psychological violence from the MIP, this was $3 \%$ before pregnancy only, $2 \%$ during pregnancy only and $2 \%$ both before and during pregnancy.

Results of longitudinal analyses are presented in Table 2 and are shown graphically in Figure 2. The adjusted odds ratio (aOR) for Study Group indicates the extent to which violence at baseline for each study group differed from the Near Limit Abortion Group. Months indicates change over time in violence for the Near Limit Abortion Group and the $P$ value for months indicates whether the slope of change over time statistically differed from zero. $P$ values for Study Group X Time interactions indicate whether change over time differed for that study group versus change over time for the Near Limit Abortion group.

Models adjust for: baseline age, race, employment, union status, raising children, depression/anxiety history, child abuse/neglect history, problem alcohol use prior to pregnancy recognition, recent drug use and having a household member with a drinking or drug problem or a psychiatric disorder during childhood.

There were no statistically significant differences in physical violence from the MIP in the six months prior to baseline across study groups. Physical violence from the MIP decreased over time for the Near Limit Group (aOR 0.93, $P<.001$ ) (See Table 2, Figure 2). Change in physical violence over time was similar in the Turnaway No Births and First Trimester groups as in the Near 
Table 1 Baseline characteristics across study group

\begin{tabular}{|c|c|c|c|c|c|}
\hline \multirow[t]{3}{*}{ Participant characteristic } & \multirow{2}{*}{$\begin{array}{l}\text { Total } \\
\text { number }=862\end{array}$} & \multirow{2}{*}{$\begin{array}{l}\begin{array}{l}\text { Near limit } \\
\text { abortion }\end{array} \\
\text { number }=405\end{array}$} & \multirow{2}{*}{$\begin{array}{l}\begin{array}{l}\text { Turnaway } \\
\text { births }\end{array} \\
\text { number }=156\end{array}$} & \multirow{2}{*}{$\begin{array}{l}\text { Turnaway } \\
\text { no births } \\
\text { number }=48\end{array}$} & \multirow{2}{*}{$\begin{array}{l}\text { First -trimester } \\
\text { abortion } \\
\text { number }=253\end{array}$} \\
\hline & & & & & \\
\hline & & & mean (SD) or \% & & \\
\hline Age, years & $24.9(5.8)$ & $25.0(5.9)$ & $23.5(5.6) * *$ & $24.5(6.3)$ & $25.8(5.7)+$ \\
\hline Race/ethnicity & & & & & * \\
\hline White & 33 & 32 & 25 & 44 & 39 \\
\hline Black & 32 & 31 & 35 & 27 & 32 \\
\hline Hispanic/Latina & 22 & 21 & 28 & 13 & 21 \\
\hline Other & 13 & 16 & 13 & 17 & 8 \\
\hline Employed & 54 & 55 & $40 * *$ & 50 & $64 *$ \\
\hline Gestational age, weeks & $16.9(7.0)$ & $19.9(4.0)$ & $23.3(3.4) * * *$ & $18.9(3.9) * * *$ & $7.6(2.3)^{* * *}$ \\
\hline \multicolumn{6}{|l|}{ Union status } \\
\hline Married & 9 & 8 & 10 & 6 & 11 \\
\hline Cohabiting & 18 & 18 & 13 & 17 & 21 \\
\hline Not-cohabiting, never married & 63 & 63 & 72 & 61 & 57 \\
\hline Divorced/widowed & 10 & 11 & 5 & 17 & 11 \\
\hline Raising children & & & * & & \\
\hline No live births & 38 & 34 & 47 & 42 & 38 \\
\hline Living with all biological children & 53 & 56 & 42 & 52 & 55 \\
\hline Has $1+$ children cared for by someone else & 9 & 9 & 11 & 6 & 7 \\
\hline History of child abuse/neglect & 26 & 26 & 26 & $13^{*}$ & 27 \\
\hline \multicolumn{6}{|l|}{ Family history before age 18} \\
\hline Household member drinking/drug problem & 20 & 21 & 15 & $6^{*}$ & 25 \\
\hline Household member psychological disorder & 11 & 8 & 8 & 6 & $18^{* * *}$ \\
\hline Previous depression or anxiety diagnosis & 25 & 23 & 20 & 29 & 30 \\
\hline Alcohol problem symptom & 6 & 4 & 7 & 10 & 7 \\
\hline Recent drug use & 14 & 13 & 13 & 8 & 18 \\
\hline Physical violence from MIP prior six months & 5 & 6 & 3 & 4 & 4 \\
\hline Psychological violence from MIP prior six months & 3 & 3 & 3 & 4 & 4 \\
\hline
\end{tabular}

$+P<.10,{ }^{*} P<.05,{ }^{* *} P<.01,{ }^{* * *} P<.001$. MIP, man involved in the pregnancy.

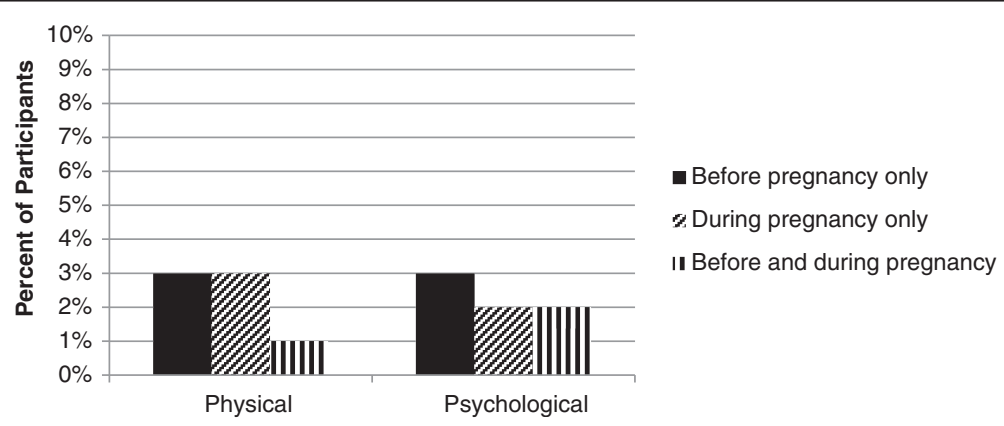

Figure 1 Violence from the man involved in the pregnancy over the past year, baseline. 
Table 2 Multivariate mixed effects logistic regressions of physical and psychological violence from the man involved in the pregnancy over 2.5 years

\begin{tabular}{llll}
\hline Physical violence (number $=848$ ) & & & \\
\hline & aOR & $P$ value & $95 \% \mathrm{Cl}$ \\
\hline
\end{tabular}

\section{Study Group}

Near Limit Abortion Group

Turnaway Births

Turnaway No Birth

First Trimester Abortion Group

Time

Months

Study Group X Time interactions

$\begin{array}{lllll}\text { Turnaway Births X months } & 1.06 & 0.047 & 1.00 & 1.12 \\ \text { Turnaway No Birth X months } & 0.93 & 0.406 & 0.78 & 1.11 \\ \text { First Trimester X months } & 1.02 & 0.324 & 0.98 & 1.07\end{array}$

Psychological violence (number $=849$ )

\begin{tabular}{lccccc} 
& aOR & $P$ value & \multicolumn{2}{c}{$95 \% \mathrm{Cl}$} \\
Study Group & & & & \\
Near Limit Abortion Group & ref & & & \\
Turnaway Births & 0.97 & 0.962 & 0.33 & 2.85 \\
Turnaway No Birth & 2.47 & 0.290 & 0.46 & 13.14 \\
First Trimester Abortion Group & 1.28 & 0.564 & 0.56 & 2.91 \\
Time & & & & \\
Months & 0.97 & 0.043 & 0.94 & 1.00 \\
Study Group X Time interactions & & & & \\
Turnaway Births X months & 1.02 & 0.451 & 0.97 & 1.08 \\
Turnaway No Birth X months & 0.83 & 0.126 & 0.66 & 1.05 \\
First Trimester X months & 1.02 & 0.394 & 0.98 & 1.06 \\
\hline
\end{tabular}

aOR, adjusted odds ratio; $\mathrm{Cl}$, confidence interval.
Limit group. However, change in physical violence differed over time between Turnaway Births and the Near Limit Abortion Group (aOR 0.98 for Turnaway Births, $P=.047$ compared to Near Limits). In a model with Turnaway Births as the reference group, the $P$-value for change over time was not significant $(P=0.396)$. This indicates that, unlike the other three groups, the Turnaway Births group did not experience a statistically significant decrease in physical violence from the MIP over time.

Psychological violence from the MIP decreased over time for the Near Limit Abortion Group $(\mathrm{aOR}=0.97, P=.043)$ (See Table 2), with no differences at baseline or in change over time by study group; all groups experienced decreased psychological violence from the MIP.

\section{Discussion}

Among women seeking abortion, having an abortion was associated with a reduction over time in physical violence from the MIP, while carrying the pregnancy to term was not. Terminating an unwanted pregnancy may allow women to avoid physical violence from the MIP, while having a baby from an unwanted pregnancy appears to result in sustained physical violence over time. This finding is consistent with our hypothesis that having a baby with an abusive man, compared to terminating the unwanted pregnancy, makes it harder to leave the abusive relationship. It is also consistent with findings from analyses of relationship outcomes among women in the Turnaway Study sample [19]. These analyses found that women denied abortions were slower to end their romantic relationships with the MIPs than women having abortions, with differences in romantic involvement disappearing by two years post-abortion seeking. They also found that women denied abortion were more likely to have sustained contact with the MIP over time. Notably, women having firsttrimester abortions and women initially denied abortions who did not end up giving birth experienced similar reductions in violence as those having near-limit abortions.

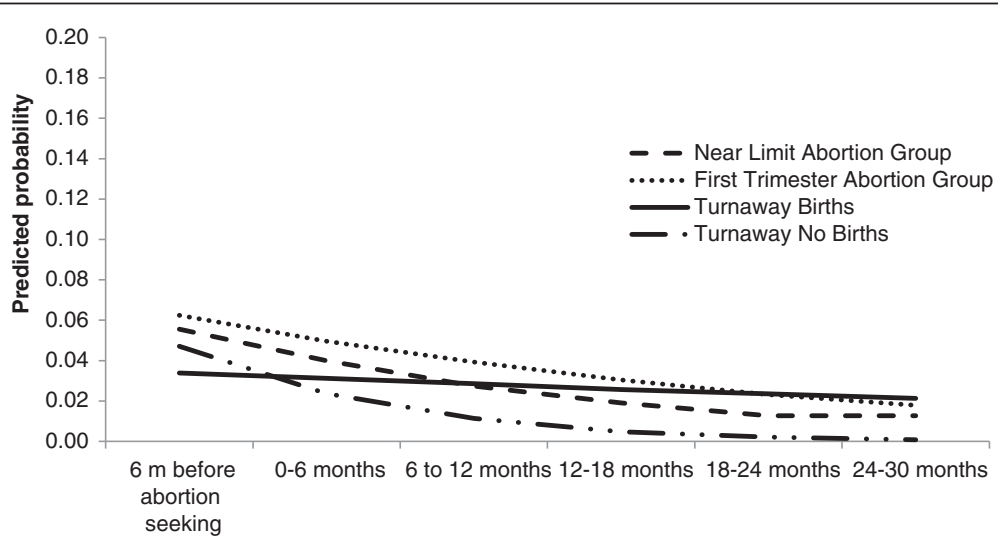

Figure 2 Physical violence from the man involved in the pregnancy. 
IPV has serious health consequences for women, including injury, chronic pain, gastrointestinal problems, sexually-transmitted infections, depression and posttraumatic stress disorder [20]. The fact that women who had babies resulting from unwanted pregnancies had more ongoing physical violence is of particular concern, as the violence can also affect their children. Violence during pregnancy is associated with negative birth outcomes, including low birth weight, pre-term delivery and neonatal death [21], and children exposed to IPV are at increased risk of emotional and behavioral problems [22,23]. Ensuring that women unable to terminate unwanted pregnancies receive support and interventions around violence is of utmost importance; guidance is provided in a recent American College of Obstetricians and Gynecologists Opinion [24]. We found no differences in reports of violence prior to abortion seeking by study group; women who sought near-limit abortions did not report more violence than women who sought earlier abortions.

Some limitations are worth noting. First, women in the Near Limit group received abortions later in gestation than typical in the U.S. [17]; thus, it is unclear whether their experiences generalize to the more typical experience. However, when we compared women receiving abortions near gestational limits to women receiving first trimester abortions, we found no differential change over time. Second, violence from the MIP is based on who perpetrated the most recent episode of violence. If women were experiencing violence from multiple sources and the MIP was not the most recent source of violence, this may underestimate violence from the MIP. Third, information about violence from the MIP is based on self-reports by the woman experiencing the violence and may be under-reported. It is worth noting, though, that the proportion reporting violence from the MIP is in the range of estimates of past year intimate partner violence reported in other studies of abortion patients $[2,3]$. Fourth, the response rate is $37.5 \%$ and those who did not participate could differ from those who did participate on key characteristics. A recent review found that most prospective cohort studies published in high impact journals did not report participation information [25], meaning that published response rates for prospective cohort studies may suffer from reporting bias, with only those with higher rates reporting them [26]. The $37.5 \%$ response rate for a five year study with biannual interviews of women seeking a stigmatized health service is within the range of other large-scale prospective studies. Importantly, our exposure (receiving versus being denied abortion) was not associated with nonparticipation. Because the topic of violence was not raised when potential participants were initially informed about the study, non-participation is unlikely to be related to violence outcomes. Fifth, our violence measures did not capture severity or frequency of violence.

This study also has a number of strengths. First, the Turnaway Study is the first study of abortion and subsequent intimate partner violence to use a comparison group for women receiving abortions that best represents what women's experiences would have been had they not been able to terminate their pregnancies. It is also a prospective study that was designed to assess experiences and health subsequent to abortion and, thus, does not rely on retrospective reports of abortion. Second, we found similar proportions experiencing violence from the MIP in the past year to previous studies of IPV among women having abortions, suggesting that the experiences of women in our sample may be typical of those of other women seeking abortion [2,3]. Third, retention was high, with $72 \%$ of participants retained at the sixth interview and no differential loss to follow-up by study group.

\section{Conclusions}

In summary, physical violence from the MIP decreased over time for women having abortions but not for women denied abortions. This finding is concerning, especially in light of the increasing number of state-based restrictions that limit women's access to abortion care in the U.S. Policies that restrict abortion provision may result in more women being unable to terminate unwanted pregnancies, potentially keeping some women in physically violent relationships, and putting both women and their children at increased risk of violence and other negative health consequences.

\section{Competing interests}

The authors declare they have no competing interests.

\section{Authors' contributions}

DGF designed and implemented the study and contributed to the interpretation of the statistical results. SCMR guided the data analysis, wrote the first draft of the paper and oversaw the interpretation of the statistical results. KSC conducted preliminary analyses, reviewed the literature and contributed to the interpretation of the statistical results. MAB conducted the final data analyses and contributed to the interpretation of the statistical results. $\mathrm{HG}$ reviewed the literature. CHR contributed to the interpretation of the statistical results. All authors contributed to drafting and revising the article. All authors read and approved the final manuscript.

\footnotetext{
Acknowledgments

Components of this study were funded by the Wallace Alexander Gerbode Foundation, The William and Flora Hewlett Foundation, the David and Lucile Packard Foundation and an anonymous foundation. The authors thank Rana Barar and Sandy Stonesifer for study coordination and management; Janine Carpenter, Undine Darney, Ivette Gomez, Selena Phipps, Claire Schreiber and Danielle Sinkford for conducting interviews; Michaela Ferrari and Elisette Weiss for project support; and Jay Fraser and John Neuhaus for database and statistical assistance. Preliminary findings from this study were presented at the American Public Health Association Conference in San Francisco, CA in October 2012
}

Received: 29 May 2014 Accepted: 4 August 2014

Published online: 29 September 2014 


\section{References}

1. Pallitto CC, Garcia-Moreno C, Jansen HA, Heise L, Ellsberg M, Watts C: Intimate partner violence, abortion, and unintended pregnancy: results from the WHO multi-country study on women's health and domestic violence. Int J Gynaecol Obstet 2013, 120:3-9.

2. Saftlas AF, Wallis AB, Shochet T, Harland KK, Dickey P, Peek-Asa C: Prevalence of intimate partner violence among an abortion clinic population. Am J Public Health 2010, 100:1412-1415.

3. Jones RK, Moore AM, Frohwirth LF: Perceptions of male knowledge and support among U.S. women obtaining abortions. Womens Health Issues 2011, 21:117-123.

4. Evins $\mathrm{G}$, Chescheir N: Prevalence of domestic violence among women seeking abortion services. Womens Health Issues 1996, 6:204-210.

5. Glander SS, Moore ML, Michielutte R, Parsons LH: The prevalence of domestic violence among women seeking abortion. Obstet Gynecol 1998, 91:1002-1006.

6. Chibber KS, Biggs MA, Roberts SC, Foster DG: The role of intimate partners in women's reasons for seeking abortion. Womens Health Issues 2014, 24:e131-138.

7. Biggs MA, Gould H, Foster DG: Understanding why women seek abortions in the US. BMC Womens Health 2013, 13:29.

8. Finer LB, Frohwirth LF, Dauphinee LA, Singh S, Moore AM: Reasons U.S. women have abortions: quantitative and qualitative perspectives. Perspect Sex Reprod Health 2005, 37:110-118.

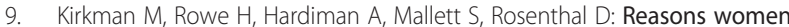
give for abortion: a review of the literature. Arch Womens Ment Health 2009, 12:365-378.

10. Fergusson DM, Boden JM, Horwood LJ: Abortion among young women and subsequent life outcomes. Perspect Sex Reprod Health 2007, 39:6-12.

11. Rocca C, Kimport K, Gould H, Foster D: Women's emotional responses to unintended pregnancy, abortion and being denied an abortion in the United States. Perspect Sex Reprod Health 2013, 45:122-131.

12. Roberts SC, Avalos LA, Sinkford D, Foster DG: Alcohol, tobacco and drug use as reasons for abortion. Alcohol Alcohol 2012, 47:640-648.

13. Gould H, Perrucci A, Barar R, Sinkford D, Foster D: Patient education and emotional support practices in abortion care facilities in the United States. Womens Health Issues 2012, 22:e359-e364.

14. Upadhyay UD, Weitz TA, Jones RK, Barar RE, Foster DG: Denial of abortion because of provider gestational age limits in the United States. Am J Public Health. in press.

15. Roberts SC, Rocca CH, Foster DG: Receiving versus being denied an abortion and subsequent drug use. Drug Alcohol Depend 2014, 134:63-70.

16. Dobkin L, Gould H, Barar R, Ferrari M, Weiss E, Foster DG: Implementing a prospective study of women seeking abortion in the United States: understanding and overcoming barriers to recruitment. Womens Health Issues 2014, 24:e115-123.

17. Pazol K, Zane S, Parker WY, Hall LR, Gamble SB, Hamdan S, Berg C, Cook DA, Centers for Disease Control and Prevention (CDC): Abortion surveillance United States, 2007. MMWR 2011, 60:1-42.

18. California Department of Public Health Maternal Child, and Adolescent Health Program: Maternal and Infant Health Assessment Survey. 2005. Available at: http://www.cdph.ca.gov/data/surveys/MIHA/Pages/ MaternalandInfantHealthAssessment(MIHA)survey.aspx. Accessed January 10, 2014

19. Mauldon J, Foster DG, Roberts SC: Effect of abortion vs. carrying to term on a woman's relationship with the man involved in the pregnancy. Perspect Sex Reprod Health. in press.

20. Campbell JC: Health consequences of intimate partner violence. Lancet 2002, 359:1331-1336.

21. Sarkar NN: The impact of intimate partner violence on women's reproductive health and pregnancy outcome. J Obstet Gynaecol 2008, 28:266-271.

22. Wolfe DA, Crooks CV, Lee $V$, Mclntyre-Smith A, Jaffe PG: The effects of children's exposure to domestic violence: a meta-analysis and critique. Clin Child Fam Psychol Rev 2003, 6:171-187.

23. Evans S, Davies C, DiLillo D: Exposure to domestic violence: a meta-analysis of child and adolescent outcomes. Aggress Violent Behav 2008, 13:131-140.
24. ACOG Committee Opinion No. 518: Intimate partner violence. Obstet Gynecol 2012, 119:412-417.

25. Morton LM, Cahill J, Hartge P: Reporting participation in epidemiologic studies: a survey of practice. Am J Epidemiol 2006, 163:197-203.

26. Galea S, Tracy M: Participation rates in epidemiologic studies. Ann Epidemiol 2007, 17:643-653.

doi:10.1186/s12916-014-0144-z

Cite this article as: Roberts et al:: Risk of violence from the man involved in the pregnancy after receiving or being denied an abortion. BMC Medicine 2014 12:144

\section{Submit your next manuscript to BioMed Central and take full advantage of:}

- Convenient online submission

- Thorough peer review

- No space constraints or color figure charges

- Immediate publication on acceptance

- Inclusion in PubMed, CAS, Scopus and Google Scholar

- Research which is freely available for redistribution

Submit your manuscript at www.biomedcentral.com/submit
C Biomed Central 